\title{
Chromosome Evolution in African Cichlid Fish: Contributions from the Physical Mapping of Repeated DNAs
}

\author{
I.A. Ferreira ${ }^{a} \quad$ A.B. Poletto ${ }^{\text {a }} \quad$ T.D. Kocher ${ }^{b} \quad$ J.C. Mota-Velasco ${ }^{c}$ D.J.Penman ${ }^{c}$ \\ C. Martins ${ }^{a}$

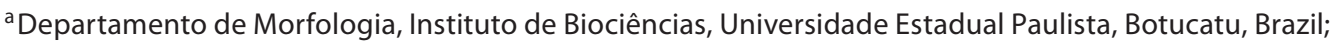 \\ ${ }^{b}$ Department of Biology, University of Maryland, College Park, Md., USA; ' Institute of Aquaculture, University of \\ Stirling, Stirling, Scotland, UK
}

\section{Key Words}

Chromosomal rearrangements $\cdot$ Cichlidae $\cdot$ Genome evolution $\cdot$ Molecular cytogenetics

\begin{abstract}
Cichlid fishes have been the subject of increasing scientific interest because of their rapid adaptive radiation that has led to extensive ecological diversity and because of their enormous importance to tropical and subtropical aquaculture. To further understanding of chromosome evolution among cichlid species, we have comparatively mapped the SATA satellite DNA, the transposable element $R O n-1$, and repeated sequences in the bacterial artificial chromosome clone BACC4E09 on the chromosomes of a range of African species of Cichlidae, using fluorescence in situ hybridization. The SATA satellite DNA was mapped in almost all the centromeres of all tilapiine and haplochromine species studied. The maintenance and centromeric distribution of the SATA satellite DNA in African cichlids suggest that this sequence plays an important role in the organization and function of the centromere in these species. Furthermore, analysis of SATA element distribution clarifies that chromosome fusions occurred independently in Oreochromis and Tilapia genera, and led to the reduced chromosome number detected in $\mathrm{O}$. karongae and
\end{abstract}

T. mariae. The comparative chromosome mapping of the ROn-1 SINE-like element and BAC-C4E09 shows that the repeated sequences have been maintained among tilapiine, haplochromine and hemichromine fishes and has demonstrated the homology of the largest chromosomes among these groups. Furthermore, the mapping of ROn-1 suggested that different chromosomal rearrangements could have occurred in the origin of the largest chromosome pairs of tilapiines and non-tilapiines.

Copyright $\odot 2010$ S. Karger AG, Basel

The family Cichlidae is one of the most species-rich families of fishes. They are present in fresh and brackish water, from Central and South America (with one species extending north to Texas, USA), to the West Indies, Africa, Madagascar, Israel, Syria, coastal India, and Sri Lan$\mathrm{ka}$ [Nelson, 2006]. This family has attracted the attention of biologists due its rapid radiation into almost 2,000 species in the Great Lakes of East Africa [Kocher, 2004]. The family Cichlidae represents a monophyletic group and the limits and interrelationships of all 4 subfamilies Etroplinae (Indian and Madagascar), Ptychochrominae (Malagasy), Cichlinae (Neotropical region) and Pseudocrenilabrinae (African) are well supported by molecular and

\section{KARGER}

Fax +4161306 1234

E-Mail karger@karger.ch

www.karger.com (c) 2010 S. Karger AG, Basel

$1424-8581 / 10 / 1294-0314 \$ 26.00 / 0$

Accessible online at:

www.karger.com/cgr
Cesar Martins

Departamento de Morfologia, Instituto de Biociências

UNESP - Universidade Estadual Paulista

Botucatu, SP 18618-000 (Brazil)

Tel./Fax +55 143811 6264, E-Mail cmartins@ibb.unesp.br 
morphological data [Sparks and Smith, 2004]. The African (Pseudocrenilabrinae) and Neotropical (Cichlinae) cichlids are both monophyletic and represent sister groups [Sparks and Smith, 2004]. Three major groups (hemichromine, haplochromine and tilapiine) can be recognized among African Pseudocrenilabrinae cichlids, but these groups are not accepted as valid taxonomic units. In addition, some species of Cichlidae, principally the tilapiines, are very important for aquaculture and fisheries, and the Nile tilapia, Oreochromis niloticus, represents one of the most widely farmed freshwater fish in the world [FAO, 2006]. Although the genomes of several African cichlid species will soon be sequenced [proposal by The International Cichlid Genome Consortium, 2006], knowledge of cichlid genomes is rather preliminary, and far behind pufferfish (Tetraodon nigroviridis) [Jaillon et al., 2004], zebrafish (Danio rerio) [Meli et al., 2008] and medaka (Oryzias latipes) [Kasahara et al., 2007]. So it is therefore of particular interest to investigate the chromosome structure of some representative taxa of the Cichlidae clade. The karyotype formulae of 135 species of cichlids have been determined [see Feldberg et al., 2003; Poletto et al., 2010, for review]. Although more than $60 \%$ of the species present a karyotype with $2 \mathrm{n}=48$, the diploid number ranges from $2 n=32$ to $2 n=60$. African cichlids have a modal diploid number of 44 chromosomes, whereas the Neotropical cichlids have $2 \mathrm{n}=48$ chromosomes. Furthermore, the chromosomal rearrangements that took place during the evolution and diversification of cichlid subfamilies remain obscure. Molecular cytogenetic techniques represent powerful tools to decipher the chromosomal rearrangements that were involved in the karyotype diversification of cichlids. Repeated DNA sequences have been extensively applied among fishes for purposes of chromosome physical mapping because they can be easily isolated from genomes and are easily visualized on chromosomes. Fishes, like many eukaryote organisms, contain a great number of tandem repeats and transposable elements in their genomes that are spread over the chromosomes, with particular enrichment in centromeric and telomeric heterochromatin, as well as the sex chromosomes [Martins, 2007]. Despite intensive study in recent decades, the molecular forces that generate, propagate and maintain repetitive DNAs in the genome are still under discussion [Biemont and Vieira, 2006]. A complete understanding of the relationship between chromosome structure and function requires the understanding of the repetitive segments. Also, the integration of DNA sequences with physical chromosome mapping of repetitive DNAs can provide a better landscape of the genome, not yet clearly defined even in the completely sequenced genomes.

Repeated DNA sequences have been applied as chromosome markers to clarify several issues involving species evolution, chromatin composition, chromosomal rearrangements, sex chromosomes, extra chromosomes, and applied genetics. To further understanding of chromosome evolution among cichlid species, we have comparatively mapped different classes of repeated DNAs in several African cichlid species. Our results contribute to an understanding of the chromosome rearrangements that took place during the evolutionary history of cichlids.

\section{Materials and Methods}

\section{Animal Samples and Chromosome Preparation}

Mitotic chromosomes of African cichlid species belonging to the Pseudocrenilabrinae subfamily (including representatives of tilapiine, haplochromine and hemichromine groups) were prepared from anterior kidney cells with in vivo colchicine treatment [Bertollo et al., 1978] or from peripheral blood leukocyte cultures [as described by Campos-Ramos et al., 2001]. The species used in this work and their origin are specified in table 1 . The species were selected based on previous information concerning the distribution of repeated DNAs that were applied as cytogenetic markers in the present work.

Chromosome Mapping of Repeated DNA Sequences through Fluorescence in situ Hybridization

Mitotic chromosome spreads were subjected to fluorescence in situ hybridization (FISH) [Pinkel et al., 1986] using the following probes: (i) SATA satellite DNA isolated from O. niloticus genome through the $\mathrm{C}_{0} t-1$ DNA method, which was used to isolate the highly repeated DNA fraction of the genome [Ferreira and Martins, 2008]. The SATA clone contains one repeat unit of SATA element (243 bp); (ii) repeated sequences contained in a bacterial artificial chromosome (BAC) library clone (\#01b03TI074A.E09), denominated BAC-C4E09, previously characterized from the genome of $O$. niloticus as containing DNA sequences with similarity to different LINE retrotransposons and satellite DNAs of cichlid and repeated dispersed sequences of Danio rerio genomes [Ferreira and Martins, 2008]; (iii) the transposable element ROn-1 previously isolated from the O. niloticus genome [Bryden et al., 1998].

The probes were labeled by nick translation with biotin-14dATP (Bionick labeling system; Invitrogen, San Diego, Calif., USA) and the hybridization performed as described in Teixeira et al. [2009]. Hybridized chromosomes were analyzed using an Olympus BX 61 microscope and the images captured with a digital camera Olympus DP71 with the software Image-ProMC 6.0. Karyotypes were arranged as meta-submetacentric $(\mathrm{m} / \mathrm{sm})$ and subtelo-acrocentric (st/a) in decreasing size of the chromosomes with Adobe Photoshop v. 7.0 software. 
Table 1. Species of Pseudocrenilabrinae African cichlids analyzed and their origin

\begin{tabular}{|c|c|c|c|}
\hline Species & Major group & $\begin{array}{l}\text { Samples analyzed } \\
(\mathrm{M}, \text { males; F, females })\end{array}$ & Origin of specimens \\
\hline Oreochromis aureus & Tilapiine & $1 \mathrm{M}$ & $\begin{array}{l}\text { Institute of Aquaculture, University of Stirling, } \\
\text { Stirling, Scotland }\end{array}$ \\
\hline Oreochromis mortimeri & Tilapiine & $1 \mathrm{~F}$ & $\begin{array}{l}\text { Institute of Aquaculture, University of Stirling, } \\
\text { Stirling, Scotland }\end{array}$ \\
\hline Oreochromis mossambicus & Tilapiine & $1 \mathrm{~F}$ & $\begin{array}{l}\text { Institute of Aquaculture, University of Stirling, } \\
\text { Stirling, Scotland }\end{array}$ \\
\hline Oreochromis niloticus & Tilapiine & $1 \mathrm{M}$ & $\begin{array}{l}\text { Institute of Aquaculture, University of Stirling, } \\
\text { Stirling, Scotland }\end{array}$ \\
\hline Tilapia rendalli & Tilapiine & $1 \mathrm{M}$ & $\begin{array}{l}\text { Institute of Aquaculture, University of Stirling, } \\
\text { Stirling, Scotland }\end{array}$ \\
\hline Tilapia zillii & Tilapiine & $1 \mathrm{M}, 1 \mathrm{~F}$ & $\begin{array}{l}\text { Institute of Aquaculture, University of Stirling, } \\
\text { Stirling, Scotland }\end{array}$ \\
\hline Tilapia mariae & Tilapiine & $1 \mathrm{~F}$ & $\begin{array}{l}\text { Tropical Aquaculture Facility, University of } \\
\text { Maryland, College Park, Md., USA }\end{array}$ \\
\hline Hemichromis bimaculatus & Hemichromine & $1 \mathrm{~F}$ & Aquarium, Botucatu, SP, Brazil \\
\hline Astatotilapia burtoni & Haplochromine & $1 \mathrm{~F}$ & $\begin{array}{l}\text { Tropical Aquaculture Facility, University of } \\
\text { Maryland, College Park, Md., USA }\end{array}$ \\
\hline Haplochromis obliquidens & Haplochromine & $1 \mathrm{~F}, 3 \mathrm{M}$ & Aquarium, Botucatu, SP, Brazil \\
\hline Melanochromis auratus & Haplochromine & $1 \mathrm{M}$ & Aquarium, Botucatu, SP, Brazil \\
\hline Labeotropheus trewavasae & Haplochromine & 1 unidentified sex & Aquarium, Botucatu, SP, Brazil \\
\hline
\end{tabular}

\section{Results}

The SATA clone was used as a probe for chromosome mapping, through FISH, in the chromosomes of O. niloticus, O. aureus, O. mossambicus, O. mortimeri, T. mariae, T. rendalli, T. zillii, H. obliquidens and M. auratus (fig. 1). The SATA satellite mapped in the centromeric areas of the different species of African cichlids analyzed (fig. 1). In O. niloticus, O. aureus, O. mossambicus, O. mortimeri, T. rendalli and $H$. obliquidens the SATA sites were distributed in all centromeres (fig. la-c, e, f, h), whereas T. mariae, M. auratus and T. zillii showed some chromosomes without SATA labeling in their centromeric areas (fig. 1d, g, i). In T. zillii the SATA element occupied the centromeric area of only one homologous member of the largest pair (fig. 1i).

The BAC-C4E09 probe was mapped in the chromosomes of $O$. niloticus, $H$. obliquidens, $M$. auratus and $L$. trewavasae (fig. 2). In O. niloticus, BAC-C4E09 hybridized across the entire extent of chromosome pair 4 (the largest pair), except around its centromeric area (fig. 2a). The chromosome signals generated after hybridization of BAC-C4E09 allowed the identification of several chromosome elements in the karyotype of O. niloticus, including pairs 1-9, 11, 15-19, and 22. The largest chromosome pair of $O$. niloticus has been referred to as pair 1 in other studies because the arrangement of the karyotype was based on chromosome size [Oliveira and Wright, 1998; Ferreira and Martins, 2008; Ocalewicz et al., 2009; Valente et al., 2009]. BAC-C4E09 showed strong signals in the short arm of the largest $\mathrm{m} / \mathrm{sm}$ chromosome pair (pair 1) of the non-tilapiine species, in the telomeric region of the st/a chromosome pair 12 of H. obliquidens (fig. 2b), in the centromeric/short arm regions of chromosome pairs 4, 5, 8, 11, 13 and 19 of M. auratus (fig. 2c), and in an interstitial position of chromosome pair 11 of $L$. trewavasae (fig. 2d). Scattered faint signals of BAC-C4E09 were also observed in the long arm of the largest chromosome (pair 1) of the non-tilapiines (fig. 2). 


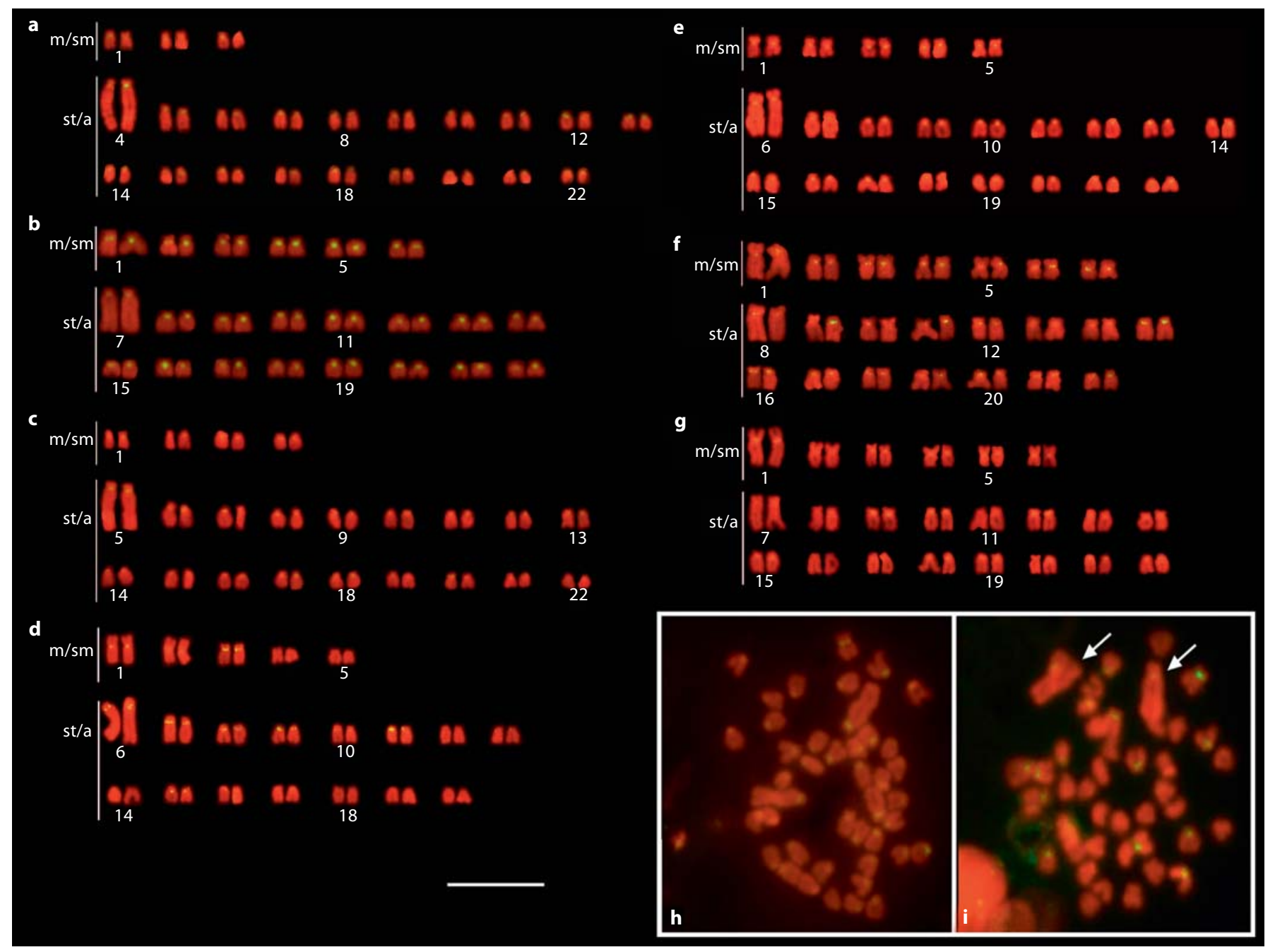

Fig. 1. Chromosome mapping of SATA satellite DNA in Oreochromis niloticus (a), Oreochromis aureus (b), O. mossambicus (c), Tilapia mariae (d), Tilapia rendalli (e), Haplochromis obliquidens (f), Melanochromis auratus (g), O. mortimeri (h) and Tilapia zillii (i). a-g represent arranged karyotypes, and $\mathbf{h}$, i metaphase spreads.

The ROn- 1 transposable element was mapped by FISH in the chromosomes of O. niloticus, A. burtoni, H. obliquidens, $M$. auratus and $H$. bimaculatus, and showed only one interstitial cluster in the long arm of the largest chromosome pair, being pair 4 in O. niloticus, and pair 1 in the non-tilapiines (fig. 3). In O. niloticus the ROn-1 signal is in the middle of the long arm of st/a chromosome pair 4 (fig. 3a), whereas in the non-tilapiines the ROn-1 cluster is near the end of the chromosome (subtelomeric) (fig. 3b-e).
The chromosomal sites of the SATA satellite were labeled with FITC (yellow) and the chromosomes were counterstained with propidium iodide (red). The meta-submetacentric $(\mathrm{m} / \mathrm{sm})$ and the subtelo-acrocentric (st/a) chromosomes are indicated. The arrows indicate the first chromosome pair in i. Bar $=5 \mu \mathrm{m}$.

\section{Discussion}

Chromosome Mapping of SATA Satellite DNA

The SATA satellite DNA is a family of tandem repeat sequences with 3 size variants, type I (237 bp), type II (230 bp) and type III (209 bp), conserved in the genome of tilapiine and haplochromiine cichlid species and absent from the genome of hemichromines [Franck et al., 1992, 1994]. In some Oreochromis species this sequence represents $1.6 \%$ of the haploid genome content, but the proportion is somewhat lower in haplochromine genomes. This difference may indicate a major amplification of the 


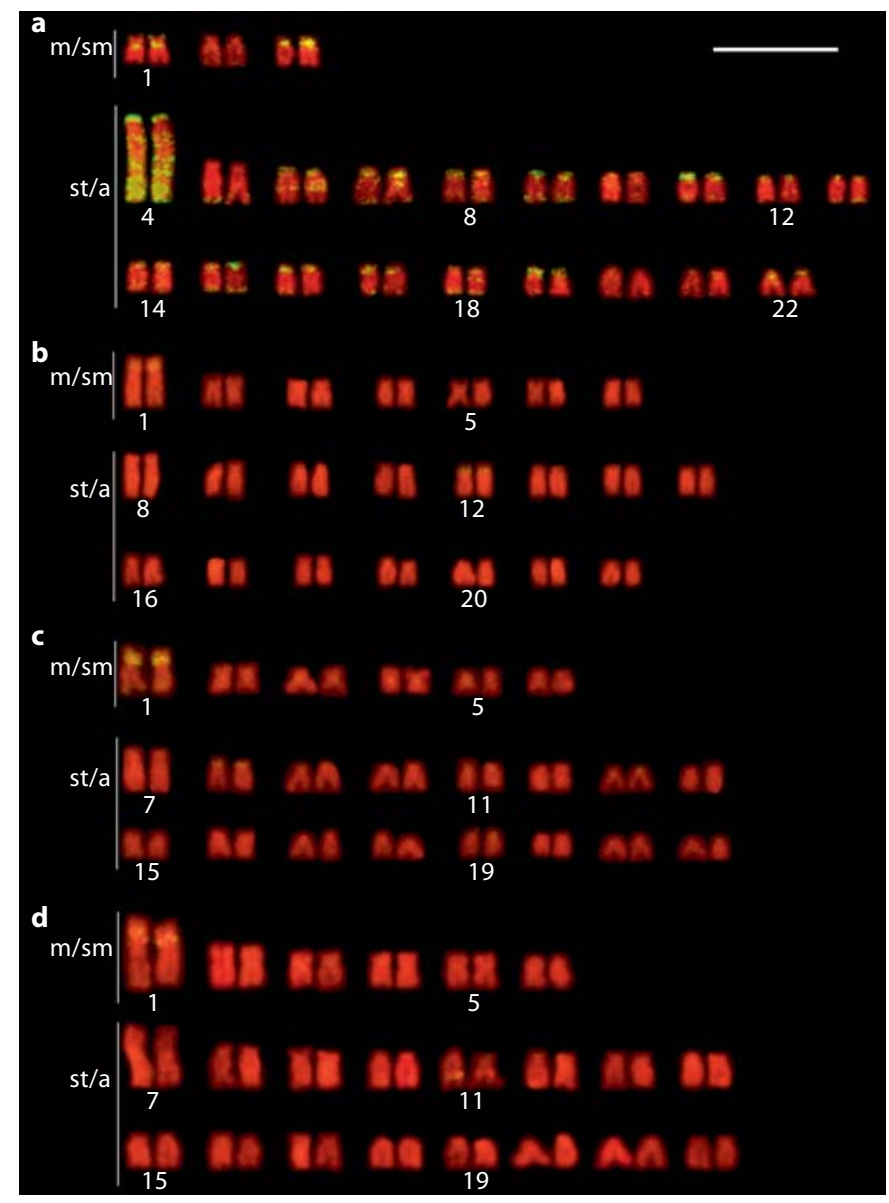

Fig. 2. Chromosome mapping of the clone BAC-C4E09 in Oreochromis niloticus (a), Haplochromis obliquidens (b), Melanochromis auratus (c) and Labeotropheus trewavasae (d). The chromosomal sites of the BAC-C4E09 were labeled with FITC (yellow) and the chromosomes were counterstained with propidium iodide (red). The meta-submetacentric $(\mathrm{m} / \mathrm{sm})$ and the subtelo-acrocentric (st/a) chromosomes are indicated. Bar $=5 \mu \mathrm{m}$.

SATA array after the divergence of the tilapiines from the haplochromine lineage [Franck et al., 1994].

The SATA satellite DNA was mapped in the centromeric area of the different species of African cichlids analyzed. In the biggest chromosome pair in T. zillii, the SATA satellite DNA was observed in the centromeric area of just one homologous member. Besides this, the hetero-

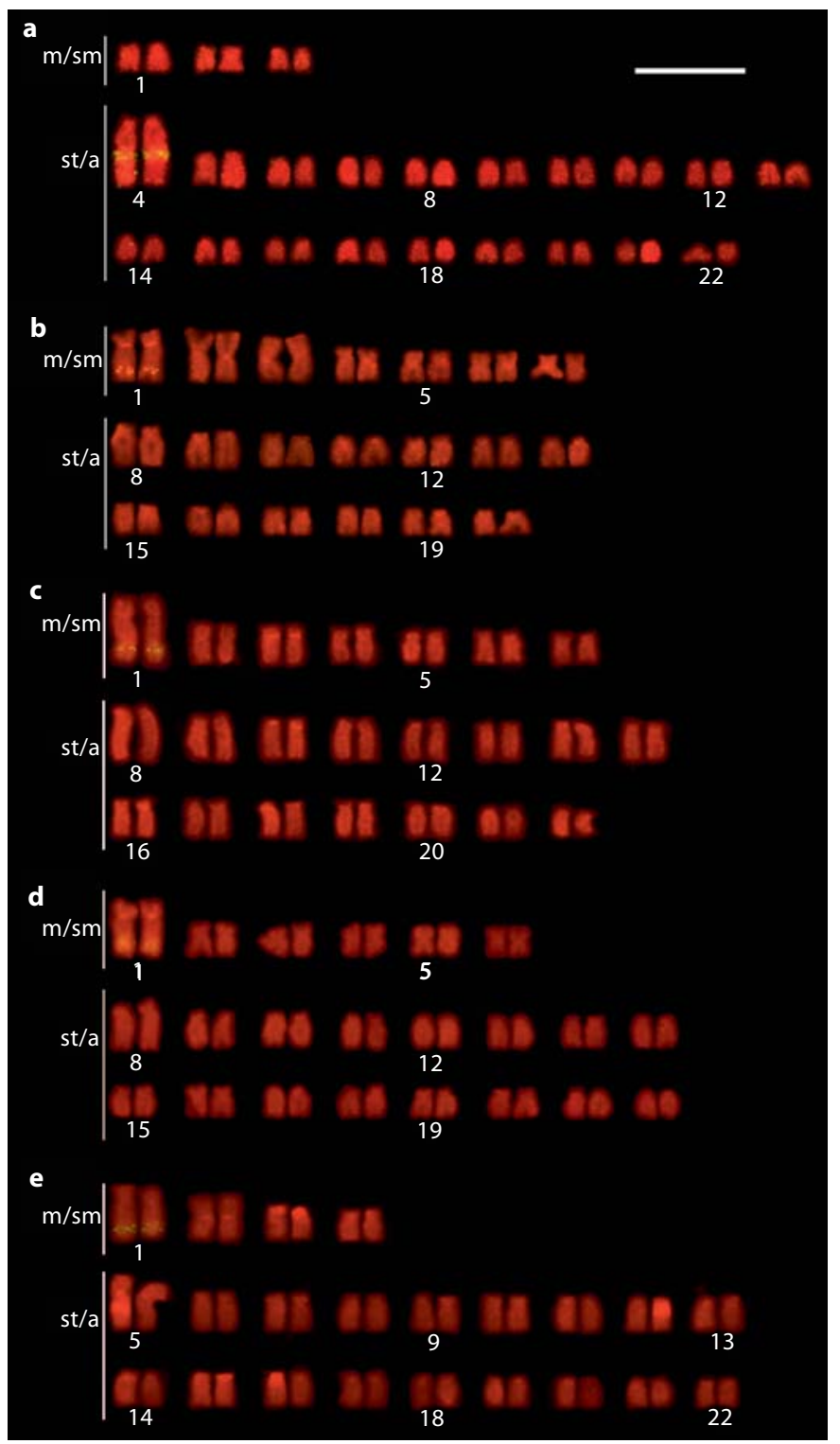

Fig. 3. Chromosome physical mapping of $\mathrm{ROn}-1$ transposon in Oreochromis niloticus (a), Astatotilapia burtoni (b), Haplochromis obliquidens (c), Melanochromis auratus (d) and Hemichromis bimaculatus (e). The meta-submetacentric ( $\mathrm{m} / \mathrm{sm})$ and the subteloacrocentric (st/a) chromosomes are indicated. Bar $=5 \mu \mathrm{m}$.

chromatin distribution analyses in T. zillii showed centromeric heterochromatin only in some chromosomes, whereas 10 to 12 chromosomes did not have clear heterochromatic blocks [Majumdar and McAndrew, 1986]. The chromosomal mapping of the centromeric SATA satellite in T. zillii seems to be related to the heterochromatin distribution, suggesting that the centromeric heterochroma- 
tin of this species is not composed of SATA satellite DNA only. The absence of SATA labeling in some chromosomes of M. auratus and T. mariae could be related to the divergence of this sequence compared to the other cichlids analyzed. Indeed, T. mariae has a divergent karyotype structure compared to the other cichlids (discussed later in this paper).

The tilapiines seem to be highly conservative in relation to karyotype evolution, with most of them showing 44 chromosomes, except for O. alcalicus with 48 chromosomes [reviewed in Feldberg et al., 2003; Poletto et al., 2010] and O. karongae with 38 chromosomes [Harvey et al., 2002]. The reduction of the chromosome number in $O$. karongae is related to the presence of 3 pairs of medium-sized chromosomes not found in typical Oreochromis species, which originated by chromosome fusion [Harvey et al., 2002]. The mapping of the SATA satellite DNA in $O$. karongae has shown signals in all centromeres and in an interstitial position in the 3 medium-sized pairs [MotaVelasco et al., in press]. The interstitial SATA sites are interpreted as relics of ancient centromeres, demonstrating that fusions occurred in the O. karongae chromosomes.

The chromosome number of T. mariae is also reduced, $2 \mathrm{n}=40$ (fig. 1d of present work) [Thompson, 1981]. This reduction could be the result of 2 different chromosome fusions giving rise to the $\mathrm{m} / \mathrm{sm}$ chromosome pairs 1 and 2 observed in T. mariae that are not observed in the other Oreochromis and Tilapia species [Majumdar and McAndrew, 1986; present work]. The SATA probe was mapped in almost all centromeres of $T$. mariae, and strongly in the $2 \mathrm{~m} / \mathrm{sm}$ largest pairs, with no interstitial signals, suggesting that the fusions occurred between 2 small st/a chromosomal pairs with the loss of their small arms. The absence of SATA in some centromeric regions in T. mariae and M. auratus could be related to differentiation in their genomes after the divergence of the other groups.

Different species of eukaryotes have shown the presence of satellite DNAs in the centromere and pericentromeric regions, implying that these sequences play a fundamentally important functional role in these regions, and also in the formation and maintenance of heterochromatin [Plohl et al., 2008]. The presence of SATA in tilapiines and haplochromines evidenced its origin before the divergence of these 2 major groups from the hemichromines. In the same way, SATA repeats seem to have differentiated or even been lost in some particular chromosomes of tilapiines and haplochromines during evolution as a consequence of their intense evolutionary dynamic.

Comparative Chromosome Mapping in Cichlids
Chromosome Mapping of BAC Clone Enriched with

Repeated DNA Sequences

BACs containing repeated DNA sequences isolated from the O. niloticus genome were previously mapped in the chromosomes of this species, which showed a distribution in centromeric, telomeric and/or interstitial regions in almost all chromosomes of the complement [Ferreira and Martins, 2008]. The most outstanding characteristic was the enrichment of repetitive DNA distribution in the large chromosome pair of O. niloticus (pair 4) [Ferreira and Martins, 2008]. The nucleotide sequencing of subcloned DNA segments of BAC-C4E09 identified the repeated DNA sequences CiLINE2 transposon and SATB satellite that were previously mapped in the chromosomes of O. niloticus [Oliveira and Wright, 1998; Oliveira et al., 1999; Harvey et al., 2003]. The CiLINE2 transposable element is distributed mainly in the largest chromosome pair of Nile tilapia and SATB satellite DNA showed a strong signal near the telomere of a small pair [Oliveira and Wright, 1998; Oliveira et al., 1999]. The mapping of BAC-C4E09 in the telomeric region of the st/a chromosome pair of H. obliquidens, in the centromeric/short arm regions of chromosome pairs of $M$. auratus, and in an interstitial position of a chromosome pair of $L$. trewavasae could be related to the presence of these repetitive sequences, mainly the SATB satellite DNA, which has been mapped in the short arm of small chromosomes in O. $n i$ loticus [Oliveira et al., 1999].

The presence of large blocks of hybridization of BACC4E09 in the largest chromosome pair of O. niloticus (pair 4) and in the largest chromosome pair (pair 1) of all the non-tilapiine species analyzed, suggests homology between these chromosomes.

\section{Chromosome Mapping of ROn-1 Transposable \\ Element}

The $R O n-1$ repeated sequence is a SINE-like element that was isolated from $O$. niloticus and represents a potential marker for evolutionary and phylogenetic studies because variant forms are specific to a particular taxonomic unit [Bryden et al., 1998]. This element is $345 \mathrm{bp}$ long and the haploid genome of tilapia contains approximately 3,000 copies [Oliveira et al., 2003]. Southern blot hybridization indicated the presence of $R O n-1$ in the genomes of the tilapiines Oreochromis, Sarotherodon and Tilapia, several haplochromine species, and in Hemichromis and Pelvicachromis [Bryden et al., 1998].

Chromosome mapping of the $\mathrm{ROn}-1$ transposable element in tilapiine and non-tilapiine species showed a conservation of this sequence in a cluster in the long arm of

Cytogenet Genome Res 2010;129:314-322 
the largest chromosome pair of the species analyzed. In O. niloticus the ROn-1 signal is in the middle of the long arm of the largest pair (pair 4). Although some previous studies have detected dispersed $\mathrm{ROn}-1$ signals in several chromosomes of the complement of O. niloticus [Harvey et al., 2003; Oliveira et al., 2003], this was not observed in the present analysis. In the other cichlid species analyzed in this work, this transposable element is clustered near the terminal position in the long arm of the largest $\mathrm{m} / \mathrm{sm}$ pair (pair 1). These results indicate that the cluster containing the transposable element $\mathrm{ROn}-1$ is conserved between cichlid species and that the st/a chromosome pair 4 of $\mathrm{O}$. niloticus is homologous to the $\mathrm{m} / \mathrm{sm}$ chromosome pair 1 of the non-tilapiine species.

The major feature in the karyotype of tilapiine cichlids is the presence of one large st/a chromosome pair, which is significantly larger than all the others in the karyotype, and it is not present in the non-tilapiine cichlid species [Majumdar and McAndrew, 1986; Poletto et al., in preparation]. On the other hand, the haplochromine and hemichromine cichlids have shown 2 outstanding chromosome pairs, the $\mathrm{m} / \mathrm{sm}$ pair 1 and the st/a pair 2 that are larger than the rest of chromosomes in the karyotype [Poletto et al., in preparation]. According to chromosome in situ hybridization using telomeric probes, it has been proposed that the larger chromosome pair of O. niloticus originated by a centric fusion event of 3 other pairs of the ancestral cichlid karyotype composed of 48 acrocentric chromosomes [Chew et al., 2002]. Based on previous information, and in the results presented here, we propose that a first chromosome fusion took place before the divergence of the main East African cichlid groups, and reduced their karyotype from the ancestral $2 \mathrm{n}=48$ acrocentric pattern [Chew et al., 2002; Teixeira et al., 2009] to generate the proto-large chromosome of $O$. niloticus and the proto-pair 1 of the non-tilapiines (fig. 4). The second event of chromosome fusion occurred independently in the tilapiines and non-tilapiines. In the tilapiines, a new chromosome was fused to the largest pair originating the actual pair 4 . In the non-tilapiines, the second fusion involved 2 other chromosomes giving the chromosome pair 2 (fig. 4).

\section{Distribution of Repetitive DNAs and Chromosome \\ Evolution in Cichlids}

The cytogenetic mapping of repeated DNAs in cichlids provides evidence that specific patterns of chromosome rearrangements have occurred during their evolutionary history. The chromosome mapping of BACC4E09 and the ROn-1 transposable element in tilapiines

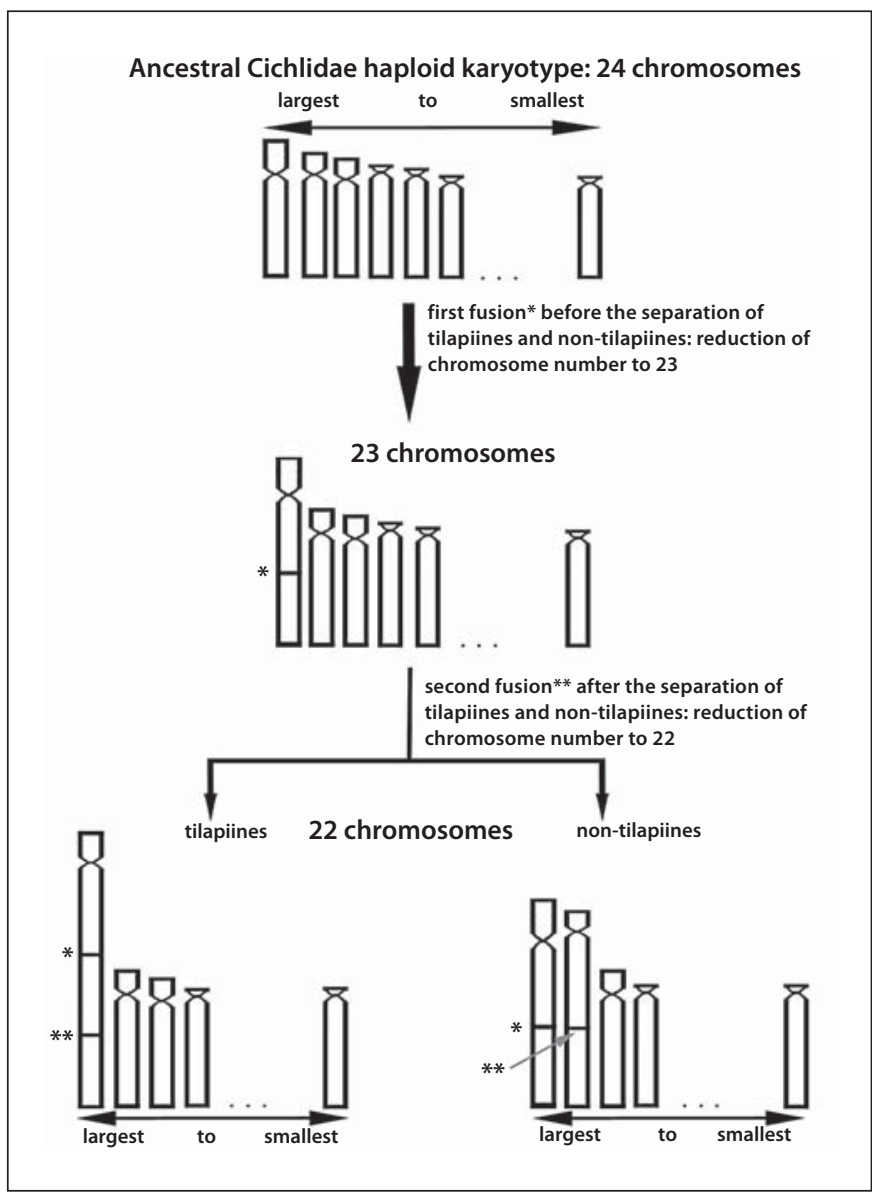

Fig. 4. Schematic representation of possible fusions occurring during the chromosomal diversification of African cichlids.

and non-tilapiines detected homology between the largest chromosome pair of the tilapiines (pair 4 in O. niloticus) and the largest $\mathrm{m} / \mathrm{sm}$ chromosome pair (pair 1) of the non-tilapiine species. It seems that 2 chromosomal fusions, the first one occurring before the divergence of the main groups of East African cichlids, and the second one occurring independently in tilapiines and non-tilapiines (fig. 4) have also occurred in the diversification of African cichlid karyotypes. Additional chromosome fusions occurred independently in Oreochromis and Tilapia genera, giving the reduced chromosome number detected in O. karongae and T. mariae (fig. 5). Besides the homology between the largest chromosome pair of tilapiines and non-tilapiine species, it seems clear that intrachromosomal inversions have occurred giving the differences in the morphology between these chromosomal elements. 
Fig. 5. Relationships of African cichlids based on the phylogenies proposed by Albertson et al. [1999] and Farias et al. [1999] showing the repeated sequences mapped in the chromosomes (colored indications). Possible chromosome fusions (/) and diploid chromosome numbers are indicated.

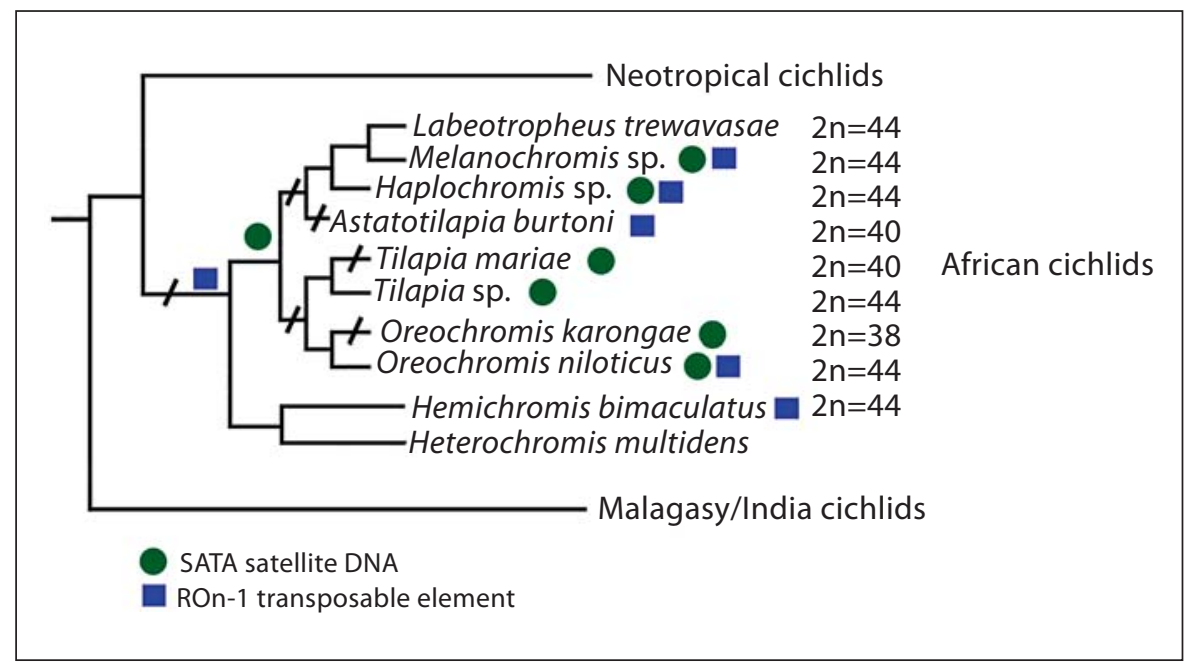

Synaptonemal complex analysis indicated that the biggest chromosome pair of $O$. niloticus represents the sex chromosomes [Foresti et al., 1993; Carrasco et al., 1999]. However, Cnaani et al. [2008] proposed that this larger chromosome pair in Nile tilapia may reflect prior evolutionary history of this pair as differentiated sex chromosomes, and that the sex determination locus is now on a small chromosome. Several repetitive sequences are distributed along the large chromosome pair of $O$. niloticus [Ferreira and Martins, 2008; Valente et al., 2009, and references cited therein] with different patterns of hybridization, due the difference in the copy number of this repetitive sequence between the supposed $X$ and Y chromosomes [Harvey et al., 2003; Ocalewicz et al., 2009]. The presence of $R O n-1$ and the repeated sequences inserted in the BAC-C4E09 clone in the largest chromosome of African cichlids suggest that the accumulation and variable copy number of these repeated sequences in this region were integral to the early differentiation of the homologous sex chromosome. Fur- ther comparative analyses of the chromosomes of other non-tilapiines and South American cichlid species may be able to clarify other chromosomal rearrangements that were involved in karyotype diversification in cichlids. The application of BACs containing single copy markers or genes as chromosomal probes represents a promising approach to clarify the events of chromosome rearrangements that took place during the evolutionary history of cichlids.

\section{Acknowledgements}

The authors are grateful to Fundação de Amparo à Pesquisa do Estado de São Paulo (FAPESP), Conselho Nacional de Desenvolvimento Científico e Tecnológico (CNPq), Coordenação de Aperfeiçoamento de Pessoal de Nível Superior (CAPES), Brazil, the Consejo Nacional de Ciencia y Tecnologia (CONACYT), Mexico, and the National Science Foundation (DEB-0445212), for financial support.

\section{References}

-Albertson RC, Market JA, Danley PD, Kocher TD: Phylogeny of a rapidly evolving clade: The cichlid fishes of Lake Malawi, East Africa. Proc Natl Acad Sci USA 96:5107-5110 (1999).

Bertollo LAC, Takahashi CS, Moreira-Filho O: Cytotaxonomic consideration on Hoplias lacerdae (Pisces, Erythrinidae). Brazilian J Genet 1:103-120 (1978).

Biemont C, Vieira C: Junk DNA as an evolutionary force. Nature 443:521-524 (2006).

Comparative Chromosome Mapping in Cichlids
Bryden LJ, Denovan-Wright EM, Wright JM: ROn-1 SINEs: a tRNA-derived, short interspersed repetitive DNA element from Oreochromis niloticus and its species-specific distribution in Old World cichlid fishes. Mol Mar Biotechnol 7:48-54 (1998).

Campos-Ramos R, Harvey SC, Masabanda JS, et al: Identification of putative sex chromosomes in the blue tilapia, Oreochromis aureus, through synaptonemal complex and FISH analysis. Genetica 111:143-153 (2001).
Carrasco LAP, Penman DJ, Bromage N: Evidence for the presence of sex chromosomes in the Nile tilapia (Oreochromis niloticus) from synaptonemal complex analysis of XX, $\mathrm{XY}$ and YY genotypes. Aquaculture 173: 207-218 (1999).

Chew JSK, Oliveira C, Wright JM, Dobson MJ: Molecular and cytogenetic analysis of the telomeric (TTAGGG)n repetitive sequences in the Nile tilapia, Oreochromis niloticus (Teleostei Cichlidae). Chromosoma 111:45-52 (2002). 
Cnaani A, Lee BY, Zilberman N, et al: Genetics of sex determination in tilapiine species. Sex Dev 2:43-54 (2008).

FAO: World aquaculture production of fish, crustaceans, mollusks, etc., by principal species in 2006. Retrieved from ftp://ftp.fao.org/ fi/stat/summary/a-6.pdf. 13/04/2009 (2006).

Farias IP, Orti G, Sampaio I, Schneider H, Meyer A: Mitochondrial DNA phylogeny of the family Cichlidae: monophyly and fast molecular evolution of the Neotropical assemblage. J Mol Evol 48:703-711 (1999).

Feldberg E, Porto JIR, Bertollo LAC: Chromosomal changes and adaptation of cichlid fishes during evolution, in Val AL, Kapoor BG (eds): Fish Adaptations, pp 285-308 (Science Publishers, Enfield 2003).

Ferreira IA, Martins C: Physical chromosome mapping of repetitive DNA sequences in Nile tilapia Oreochromis niloticus: evidences for a differential distribution of repetitive elements in the sex chromosomes. Micron 39: 411-418 (2008)

Foresti F, Oliveira C, Galetti PM, Almeida-Toledo LF: Synaptonemal complex analysis in spermatocytes of tilápia, Oreochromis niloticus (Pisces, Cichlidae). Genome 36:11241128 (1993).

Franck JPC, Wright JM, McAndrew BJ: Genetic variability in a family of satellite DNAs from tilapia (Pisces, Cichlidae). Genome 35:719725 (1992).

Franck JPC, Kornfield I, Wright JM: The utility of SATA satellite DNA sequences for inferring phylogenetic relationships among the three major genera of tilapiine cichlid fishes. Mol Phylogenet Evol 3:10-16 (1994).

Harvey SC, Masabanda J, Carrasco LAP, Bromage NR, Penman DJ, Griffin DK: Molecular cytogenetic analysis reveals sequence differences between the sex chromosomes of Oreochromis niloticus: evidence for an early stage of sex-chromosome differentiation. Cytogenet Genome Res 97:76-80 (2002).
Harvey SC, Boonphakdee C, Campos-Ramos R, et al: Analysis of repetitive DNA sequences in the sex chromosomes of Oreochromis niloticus. Cytogenet Genome Res 101:314-319 (2003).

Jaillon O, Aury JM, Brunet F, et al: Genome duplication in the teleost fish Tetraodon nigroviridis reveals the early vertebrate protokaryotype. Nature 431:946-957 (2004).

Kasahara M, Naruse K, Sasaki S, et al: The medaka draft genome and insights into vertebrate genome evolution. Nature 447:714-719 (2007).

Kocher TD: Adaptive evolution and explosive speciation: the cichlid fish model. Nature 5: 288-298 (2004).

Majumdar KC, McAndrew BJ: Relative DNA content of somatic nuclei and chromosomal studies in three genera, Tilapia, Sarotherodon, and Oreochromis of the tribe Tilapiini (Pisces, Cichlidae). Genetica 68:175-188 (1986).

Martins C: Chromosomes and repetitive DNAs: a contribution to the knowledge of fish genome, in Pisano E, Ozouf-Costaz C, Foresti F, Kapoor BG (eds): Fish Cytogenetics, pp 421-453 (Science Publisher, Enfield 2007).

Meli R, Prasad A, Patowary A, et al: FishMap: a community resource for zebrafish genomics. Zebrafish 5:125-130 (2008).

Mota-Velasco JC, Ferreira IA, Cioffi MB, Ocalewicz K, Campos-Ramos R, Shirak A, Lee BY, Martins C, Penman DJ: Characterization of the chromosome fusions in Oreochromis karongae. Chromosome Res in press (2010).

Nelson JS: Fishes of the World, 4th ed (John Wiley and Sons, New York 2006).

Ocalewicz K, Mota-Velasco JC, Campos-Ramos R, Penman DJ: FISH and DAPI staining of the synaptonemal complex of the Nile tilapia (Oreochromis niloticus) allow orientation of the unpaired region of bivalent 1 observed during early pachytene. Chromosome Res 17:773-782 (2009)

-Oliveira C, Wright JM: Molecular cytogenetic analysis of heterochromatin in the chromosomes of tilapia, Oreochromis niloticus (Teleostei: Cichlidae). Chromosome Res 6:205211 (1998).
Oliveira C, Chew JSK, Foresti FP, Dobson M, Wright JM: A LINE2 repetitive DNA sequence from the cichlid fish, Oreochromis niloticus: sequence analysis and chromosomal distribution. Chromosoma 108: 457-468 (1999).

Oliveira C, Wang Y, Bryden LJ, Wright JM: Short interspersed repetitive elements (SINEs) from the cichlid fish, Oreochromis niloticus, and their chromosomal localization by fluorescent in situ hybridization. Caryologia 56: 181-189 (2003).

Pinkel D, Straume T, Gray JW: Cytogenetic analysis using quantitative, high-sensitivity, fluorescence hybridization. Proc Natl Acad Sci USA 83:2934-2938 (1986)

Plohl M, Luchetti A, Meštrović N, Mantovani B: Satellite DNAs between selfishness and functionality: Structure, genomics and evolution of tandem repeats in centromeric (hetero)chromatin. Gene 409:72-82 (2008).

Poletto AB, Ferreira IA, Cabral-de-Mello DC, Nakajima R, Mazzuchelli J, Ribeiro HB, Venere PC, Nirchio M, Kocher TD, Martins C: Chromosome differentiation patterns during cichlid fish evolution. BMC Genetics 11:50 (2010)

Sparks JS, Smith WL: Phylogeny and biogeography of cichlid fishes (Teleostei, Perciformes, Cichlidae). Cladistics 20:501-517 (2004).

Teixeira WG, Ferreira IA, Cabral-de-Mello DC, et al: Organization of repeated DNA elements in the genome of the cichlid fish Cichla kelberi and its contributions to the knowledge of fish genomes. Cytogenet Genome Res 125:224-234 (2009).

The International Cichlid Genome Consortium: Genetic basis of vertebrate diversity: the cichlid fish model. Available at http://hcgs. unh.edu/cichlid/ (2006)

Thompson KW: Karyotypes of six species of African Cichlidae (Pisces, Perciformes). Experientia 37:351-352 (1981).

Valente GT, Schneider CH, Gross MC, Feldberg E, Martins, C: Comparative cytogenetics of cichlid fishes through genomic in-situ hybridization (GISH) with emphasis in Oreochromis niloticus. Chromosome Res 17:791799 (2009). 